the scat of reatest friction ; they are, therefore, the part to be reduced This is the reason why all animals, in a state of nature, grow thin as they grow old Man, and the creatures under his control, may violate this law, but not with impunity. Acute disease, when the arterics are decayed, is loubly dangerons. The right ventricle of the heart may be exluausted, as before, but now the left ventricle may also prove unequal. Stimulants here can have but little drawback. But in surplus lung, and an amount of blood that is well within the powers of propulsion, lies a greater safety. Obesity is dangerous to the a.ged.

It would be well to consider the phenomena of waste in fever by the light of an assumption that they are salutary. The brute creation, when suffering from fever, eat nothing, yet they do not die, but recover. The body seems destined to feed upon itself, and to delay all repair until convalescence. Great responsibility rests upon those who supersede this instinct by an artificial method. Graves, who fed fevers, at the same time bled his patients. Venesection has this drawback, that to relieve the right heart we are obliged to stint the left, and to reduce the systemic circulation to a sluggish flow. The speedy repair of such loss of blood shows that its benefit must be only temporary. Such a remedy is an imperfect substitute for a capacious lung. The perception of this inconvenience has led to the disuse of bleeding. The concomitant pressing of food in fevers should probably follow it. The most evident of natural remedies for any kind of fever are starvation and emaciation. However indulgent appetite may be in health, it returns in disease to the strictest authority. Obedience to its dictates may shatter superstitions, but will not jeopardise the cure. In chronic diseases, the physician who thinks of the future of his patient will look grudgingly on fat. It provides for warmth and irregularity of nutrition. If these be provided for in other ways, much relief can be given to the circulation; and if in acute disease the presence of a tissue should prove an embarrassment, the physician will not interfere with its removal.

Brook-street, $W$.

\section{A CASE OF PATENT FORAMEN OVALE, WITH AN ATTEMPT TO EXPLAIN} THE SYMPTOMS OBSERVED.

\section{By WALTER H. HAW, B.A., M.R.C.S. ENG., L.S.A.}

THE child in which the following symptoms occurred was born on Oct. 5th, 1889, and died on the 19th of the same month. It was a breech presentation, so I was told, and a long time elapsed before the delivery of the head. It did not cry at once after birth, was blue, and did not breathe for some time. It was also roughly handled in the attempts to deliver the head. After breathing was established the rhythm was described to be normal. On Oct. 12th the father called to tell me that the child had been yellow for some days. I told him what is known about the causation of icterus neonatorum, and to watch the child. On the 15th I was hurriedly called, as the little one had developed fresh symptoms that morning. (It is suggestive that the symptoms commenced on the tenth day, when the foramen ought normally to be closed.) This was the first time I saw the patient. 'The following notes were taken at the time.

Digestive system.--Tongue moist, white. Motions very yellow.

Respiratory system.-Breathing irregular; several quiet inspirations and expirations followed by an interval of repose. On auscultation it can be made out that during inspiration air enters the lungs fairly well. Resonance good.

Circulatory system.-The heart beats normally while breathing is going on, but at the end of the interval of repose becomes slow, full, and irregular. The lips, eyelids, nails, and generally the extremities, although their heat is fairly maintained, are cyanosed, and the circulation on pressing the fingers is found to be very languid. Emaciation is marked, there is ophthalmia due to leucorrhoea in the mother, and there are long, downy hairs scattered over the back.

On the 17th occur the following notes:-Breathing 11 per minute, three or four rapid diaphragmatic inspirations with falling in of the chest, followed by an interval, during which none are apparent either to sight or hearing. The heart acts well, there is epigastric pulsation, no murmurs, but at the end of the interval the heart shows signs of being in difficulties, becoming slower, fuller, and irregular. The pulse now becomes apparent at the wrist, disappearing during the respiratory efforts. The lips and the eyelids become blue at the end of the interral, but there is no hyperpnoea and the circulation is languid in the extremities. Micturition and defecation have been normal, but the motion to-àay is greenish. At my evening visit cold water was dropped upon the chest in order to rouse the respiratory centre, when strong inspirations resulted, but the previous condition soon returned.

Oct. 18th.--The breathing is 23 in thirty seconds. The character of the respiration remains unaltered, but the period of respiratory effort is very much nore prolonged (one minute), while the period of repose is one minute and a half. (The father states that on one occasion this morning the breathing was absent for two minutes.) The duration of each, however, varies considerably. The icteric con dition has disappeared, and the lips have a pinkish colour, except at the end of the interval of repose, when they acquire a bluish tint. The falling in of the chest during inspiration is less, but the diaphragm is the chief arent While examining the child this morning I exposed the chest for the purpose of applying the cold douche, and in watching the respiratory acts allowed the child to remain exposed for rather too long a time. The whole body became cold, and immediately afterwards intensely blue, and there were gasping respirations and irregular and slow action of the heart. The respirations were not those of asphyxia, but like those noticed immediately before death from other causes. Death appeared imminent. Warmth was immediately applied, and at once the aspect changed, the child quickly returning to the condition in which it was shortly before.

In the evening I have the following notes: The child does not swallow; mouth moist, tongue white, heart acting well. Hands and feet not so blue; breathing as usual; much emaciation. Cornea sensitive, and the pupils respond to light. Bowels \&c. normal. The child died at 12.30 A.M. on Oct. 19th. I held a partial post-mortem at $11 \mathrm{Am}$ confining myself to the heart, and my examination of this was very incomplete owing to the objection of the father to further procedure. However, I discovered a patent foramen ovale and an abnormality in the pulmonary artery, which I had no time to examine. The passage from the right auricle to the left, as shown by a blunt needle, was oblique from behind downwards and forwards, the opening in the right auricle being valve-like. The coronary sinus was seen in front of and slightly below this slit-like opening. The internal mammary vein seen on raising the sternum was full of dark blood; the coronary veins, the superior and inferior vena cavæ, were gorged, and the auricles were of 8 dark-blue colour. The lungs were pink, floated in water, and crackled on pressure. This was all I discovered in the time allowed for the examination, except that the right heart contained a dark blood-clot and the left was empty.

As no disease could be detected during life, except the icterus neonatorum, which was rather a sign of imperfect oxygenation of the blood, I was compelled to attempt diagnosis between "functional depression of the respiratory centre in the medulla," and a "probable patent foramen ovale," though I could not see how this latter in itself could account for the altered respiratory rhythm. Now, was it possible to diagnose between the conditions? It is well known that in many diseases just before dissolution occurs such rhythm of respiration takes place (Cheyne-Stokes respiration). Professor M. Foster, in his Text-book of Physiology, alludes to it in the following terms: "The cause of the phenomena is not thoroughly understood. Stokes connected it with a fatty condition of the heart, but it has been met with in various maladies. Schiff observed it as the result of compression of the medulla oblongata, and closely similar phenomena have been observed during sleep under perfectly normal con. ditions." 1

The phenomena are, I think, to be expected in cases in which it may be presumed that the nervous energy of the respiratory centre is at a low ebb. In such cases the dearterialisation of the blood would have to be very com- 
plete before a respiratory effort will appear. When it does appear, it will probably be quicker and stronger than usual, and the blood will quickly become arterialised to such a degree as to ensure rest for the depressed centre. Respiration will then be in abeyance until the blood is again sutficiently dearterialised to cause explosions in the respiratory centre. Within limits, the lower the irritability of the centre, the longer will be the period of repose. Now, the respiratory centre in this case responded well to the application of cold at first. When cyanosis appeared, and inmediately before, there was hardly any response. I suppose, then, we may conclude that its irritability was normal at first, and on the day before death was so low as hardly to respond to the stimulus. Hence it would have been an error to diagnose "functional depression of the respiratory centre." Now, supposing that this cause had been satisfactorily excluded, the diagnosis would have been "Probable patent foramen ovale." But how could this condition account for the anomalous symptoms? I inagine that the arrangernent and direction of the opening in the inter-auricular septum will account for them. The orifice in the right auricle was valve-like, the passage was oblique, and the orifice in the left auricle apyeared free for a blunt needle passed freely. What effect would this have upon the circulation?

The accompanying diagram will, I fancy, show the probable currents of blood through the heart. By following the course of the current, indicated by arrow-heads, it will be seen that in addition to an auriculo-ventricular arterial

HEART.

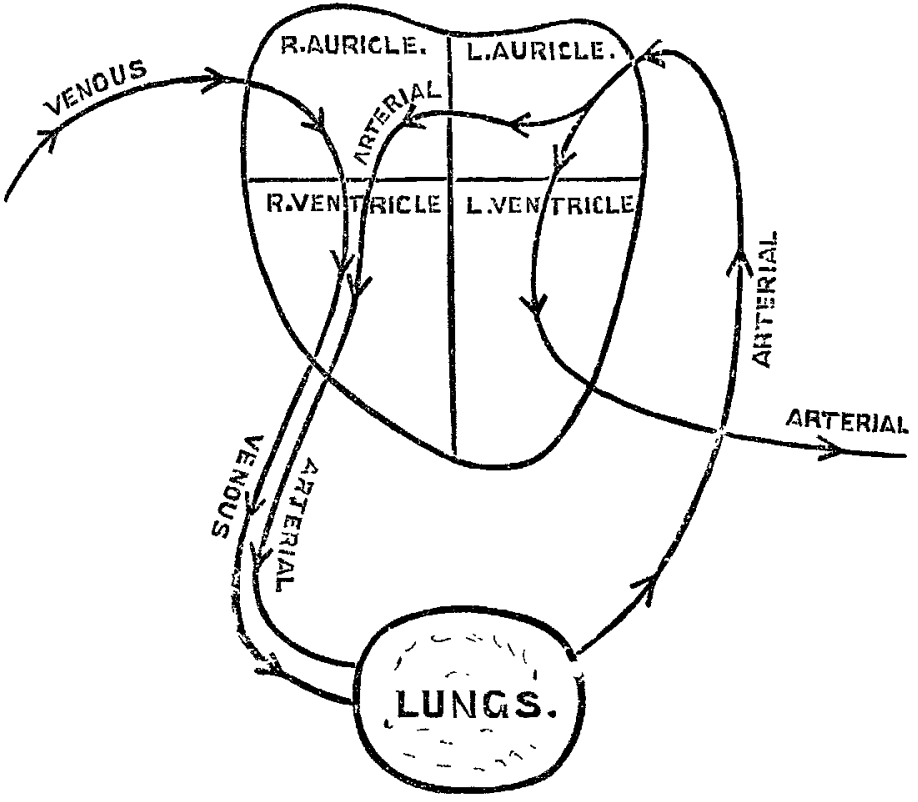

How, there is also an auriculo-auricular arterial flow from the left auricle into the right, but this occurs only during diastole of the auricles. (No murnurs of any kind were heard during life.) This flow will be favoured by the higher blood-pressure in the left auricle than in the right, even though that pressure be negative. During systole the venous blood, and the arterial blood received during diastole, are prevented from passing from the right auricle into the left by the closure of the valvular opening. Consequently there is a mixture of arterial and yenous blood in the right auricle and in the right ventricle. Mixed blood would therefore pass to the lungs through the pulmonary artery. What effects upon the heart and respiration would such a pulmonary circulation have? Can we on the basis of this method of circulation account for the symptoms and postmortem signs so far as these latter were observed.

1. The pressure in the right auricle would be higher than usual, or rather it would contain more blood than normal, and there would naturally be a backward pressure through the veins causing general venous congestion. This would account for the engorgement of the various veins mentioned when describing the post-mortem appearances.

2. The pressure in the left auriele wonld be less than normal, but probably always greater than that in the right. So would the pressure be in the left ventricle and arteries. Consequently the ventricle will contract with less force, and the pulse will tend to become imperceptible. With spuch a circulation, then, we should expect the right side of the heart to act more strongly than the left. This seems to have been probable as distinct epigastric pulsation was noticed, but the pulse at the wrist was imperceptible except at a certain period of the cycle. So much for the probable eflect of such a circulation upon the heart. What probably would be its effect upon the respiration?

Less blood needs less arterialisation in the lungs to supply the wants of the economy ; therefore fewer respirations will suffice. If the arterial leakage into the right side of the heart be copious, respiration may soon be brought to a standstill. for as lon $r$ as the richt ventricle contracts stroncrly, there will be more arterial blood than usual in circulation. Consequently, as long as this lasts, there will be no respiratory explosions. If respiration continue in abeyance, what wil be the result? No blood is freshly aerated, mixed blood passes into the pulmollary veins, and so into the left auricle and ventricle. A time arrives when there is no more arterial blood in the lungs, and if the absence of respiration were to continue, purely venous blood would be in circulation, if this were possible. The respiratory centre wakes up at a certain stage of venosity, the lungs expand, blood is aerated, and the cycle is repeated. Such a circulation, if respiration continued, would ensure an increase in the arterial blood in circulation, so long as the right ventricle did not fail. We know that this condition of the blood will ultimately stop re. spiratory explosions. Consequently breathing will ultimately cease, and will remain in abeyance until theblood is again suf ficiently venous to excite action in the centre. This venosity is brought about by the repose. Therefore the blood in circulation will be alternately more venous and more arterial, and during the venous phase there will be respiratory explosions, and, during the arterial phase, repose. To account for the other symptoms: $a$. The icterus. This was probably due to the peculiar manner in which the blood was oxygenated. When the breathing improved for a time it passed away. $\beta$. This note oscurs on Oct. 15th: "The heart beats normally while breathing is going on, but at the end of the interval of repose becomes slow, full, and irregular." It may easily be shown that the venosity of the blood is greatest at the end of the interval of repose, and this condition, in addition to the pulmonary obstruction, will put the heart into oreatest difficulty at that time. For the same reason, the lips and eyelids would be bluest at the end of the interval, and from the notes it can be seen that this was noticed. There was never any hyperpncea, except when the cold douche was applied the first time. $\gamma$. The marked effect of the cold douche in prolonging both the period of action and that of inaction seems intelligible. It roused vp the respiratory centre, and so diminished the resistance to respiratory explosions. Consequently, when it started acting, it would go on for a longer time, arterialise more blood, and allow the period of repose to be longer. A less. venous condition of blood would set it going again, and so on. $\delta$. It was noticed during this prolongation of both periods (action one minute, inaction one minute and a half) that while respiration continued the lips were pinkish, but at the end of the repose they became bluish. This was possibly due to hyperarterialisation of the blood. $\epsilon$. With regard to the symptoms resulting from the exposure, when the whole body suddenly became intensely blue and the heart almost ceased acting, $m y$ idea is that when the heart partially failed the valve-like action of the foramen did not take place, because of relaxation of the heart wall, and as the pressure was now probably equal in the two auricles, venous blood passed directly into the left auricle and set up temporarily marked general cyanosis. Warmth revived the heart, and when full action was reinduced the former circulation was resumed. It was said by the parents that towards the close the breathing became more regular, and that just before death the child became quite blue. Rustenburg, Zuid Afrikaansche Republick.

The will, dated Jan. 27 th, 1888, of the late Sir Munguldass Nuthoobboy, C.S.I., of Bombay, has been proved in London. He directs the executors of his will to build on land belonging to him, adjoining the sanatorium which he founded, a bungalow, to be used as a dispensary, for which purpose he bequeaths to them 10,000 rupees, and for the maintenance of the dispensary 30.000 rupees, and to provide a Hindoo licentiate as medical officer 30,000 rupees. He bequeaths also for the maintenance of the sanatorium 10,000 rupees, and for a temple of Shiva adjacent thereto, and the idols in the temple, 5000 rupees. The value of the testator's personal estate in England is $\mathfrak{£ 5 2 8 8 .}$ 